\title{
Cytogenetic characterization of two species of Frieseomelitta Ihering, 1912 (Hymenoptera, Apidae, Meliponini)
}

\author{
Antônio F. Carvalho and Marco Antônio Costa \\ Universidade Estadual de Santa Cruz, Departamento de Ciências Biológicas, Ilhéus, Bahia, Brazil.
}

\begin{abstract}
The cytogenetic analysis of Frieseomelitta dispar and $F$. francoi revealed the chromosome numbers $2 n=30$ and $n=15$ and a karyotypic formula $2 K=4 M+2 M^{1}+4 A+20 A^{M}$. The number of chromosomes observed was consistent with those reported for other Frieseomelitta species. The occurrence of the $M^{t}$ chromosome and other features of the karyotype formulae suggest a close relationship between $F$. dispar, F. francoi and $F$. varia. Nevertheless, it was possible to differentiate the karyotypes of the species by DAPI/CMA ${ }_{3}$ staining, which revealed GC-rich regions on two chromosome pairs of $F$. dispar. one acrocentric and one pseudoacrocentric. In $F$. francoi, the same kinds of regions were observed on a pair of metacentrics and on a pair of acrocentrics. Our analysis also confirmed the chromosome number conservation in Frieseomelitta and suggests that infrequent pericentric inversion could constitute a synapomorphy for the group including $F$. dispar, $F$. francoi, and $F$. varia.
\end{abstract}

Key words: Hymenoptera, Frieseomelitta, interspecific differentiation, C-banding, heterochromatin.

Received: July 15, 2010; Accepted: December 21, 2010.

Frieseomelitta is comprised of 16 species (Moure et al., 2007) of which only five have been cytogenetically analyzed (Rocha et al., 2003; Célia M.L.C., Moreira and Kleber F. Costa, personal communication). Previous analyses were restricted to the description of chromosome numbers and heterochromatin distribution. Although northeastern Brazil is a center of endemism for several meliponine species (Silveira et al., 2002; Moure et al., 2007), the local fauna is poorly represented in earlier cytogenetic surveys. The objective of the present study was to analyze the karyotypes of Frieseomelitta dispar and F. francoi, two closely related species from the northeastern Brazilian fauna in order to understand the types of chromosome changes that might have occurred during the differentiation of these species. To this aim, we used different cytogenetic techniques to characterize the molecular nature and patterns of distribution of constitutive heterochromatin. The placement of these two species in the available phylogeny (Camargo and Pedro, 2003) is also discussed at the light of the present results.

We analyzed specimens of $F$. dispar from four nests collected in the region of Ilhéus $\left(14^{\circ} 47^{\prime} \mathrm{S}, 39^{\circ} 12^{\prime} \mathrm{W}\right)$ and of $F$. francoi from one nest collected in Boipeba Island, municipality of Cairu $\left(13^{\circ} 30^{\prime} \mathrm{S}, 39^{\circ} 02^{\prime} \mathrm{W}\right)$, in the state of Bahia, Brazil.

Send correspondence to Marco Antônio Costa. Departamento de Ciências Biológicas, Universidade Estadual de Santa Cruz, 45662-000 Ilhéus, BA, Brazil. E-mail: costama@uesc.br.
Metaphases of 20 individuals from each nest were obtained from cerebral ganglion cells at the prepupal stage. Chromosome preparations were done according to Imai et al. (1988). A minimum of ten metaphases was analyzed per specimen. C-banding followed the protocol of Sumner (1972), with the modifications described by Pompolo and Takahashi (1990). DAPI and $\mathrm{CMA}_{3}$ staining was done according to Schweizer (1980). The best quality metaphases were photographed using a CX41 Olympus photomicroscope.

Chromosome classification and karyograms followed the nomenclature of Imai (1991), which includes metacentric chromosomes with centromeric C-bands $(\mathrm{M})$ and acrocentric chromosomes with small (A) or large heterochromatic arms $\left(\mathrm{A}^{\mathrm{M}}\right.$ or pseudoacrocentrics). A type of metacentric chromosome with centromeric and telomeric C-bands was also observed and it is herein called $\mathrm{M}^{\mathrm{t}}$. Voucher specimens were deposited in the Coleção Entomológica do Departamento de Zoologia, Universidade Federal do Paraná (DZUP), in Curitiba, Paraná State, and in the entomological collection of the Universidade Estadual de Santa Cruz (UESC).

Both species showed the chromosome numbers $2 \mathrm{n}=30$ in females and $\mathrm{n}=15$ in males. These numbers were also found in all Frieseomelitta species previously studied (Rocha et al., 2003), confirming the chromosome number conservation within the genus. These numbers are uncommon in the tribe Meliponini and have only been observed in 
the Neotropical genera Duckeola, Geotrigona, and Leurotrigona (Kerr, 1972; Pompolo and Campos, 1995; Rocha et al., 2003). Except for Duckeola, these Neotropical genera are not closely related to Frieseomelitta (Rasmussen and Cameron 2010).

We also observed the karyotypic formula $2 \mathrm{~K}=$ $4 \mathrm{M}+2 \mathrm{M}^{\mathrm{t}}+4 \mathrm{~A}+20 \mathrm{~A}^{\mathrm{M}}$ in both species. The high number of pseudoacrocentric chromosomes in these karyotypes is consistent with previous results reported for Frieseomelitta species (Rocha et al., 2003), except for $F$. trichoceratta that had the karyotypic formula $2 \mathrm{~K}=4 \mathrm{M}+16 \mathrm{~A}+10 \mathrm{~A}^{\mathrm{M}}(\mathrm{K} . \mathrm{F}$. Costa, MSc Dissertation, Universidade Federal de Mato Grosso, Cuiabá, 2003).

C-banding revealed the presence of constitutive heterochromatin in the centromeric region of metacentric chromosomes and on the short and long arms of acrocentrics and pseudoacrocetrics of both species. An $\mathrm{M}^{\mathrm{t}}$ chromosome, which is uncommon in the Meliponini, was observed in the karyotypes analyzed herein (Figure 1). This type of chromosome was previously found in F. varia. However, it was defined as an $\mathrm{A}^{\text {ct }}$ chromosome by C.M.L.C. Moreira (MSc Dissertation, Universidade Federal de Viçosa, Viçosa, 1997) and as the $10^{\text {th }}$ pair by Rocha et al. (2003). According to Imai (1991), $\mathrm{M}^{\mathrm{t}}$ chromosomes would have likely originated from an ancestral acrocentric through a pericentric inversion.

The $\mathrm{CMA}_{3} / \mathrm{DAPI}$ staining in male metaphases of $F$. dispar revealed $\mathrm{CMA}_{3}{ }^{+} / \mathrm{DAPI}^{-}$heterochromatic regions on the small arms of the $4^{\text {th }}$ chromosome pair and on the large arms of the $7^{\text {th }}$ pair (Figure $2 \mathrm{~A}$ and B). F. francoi had $\mathrm{CMA}_{3}{ }^{+} / \mathrm{DAPI}^{-}$bands in the centromeric regions of the $1^{\text {st }}$ chromosome pair and in the telomeric regions of the $4^{\text {th }}$ pair (Figure 2C and D). The molecular characterization of the heterochromatin revealed that putative homeologous heterochromatic regions are different in base composition and probably had different origins. Inferences drawn exclusively from the comparison of the C-banding results, as it is usually done, would thus be misleading. This technique was much more informative when combined with the fluorochromes staining.

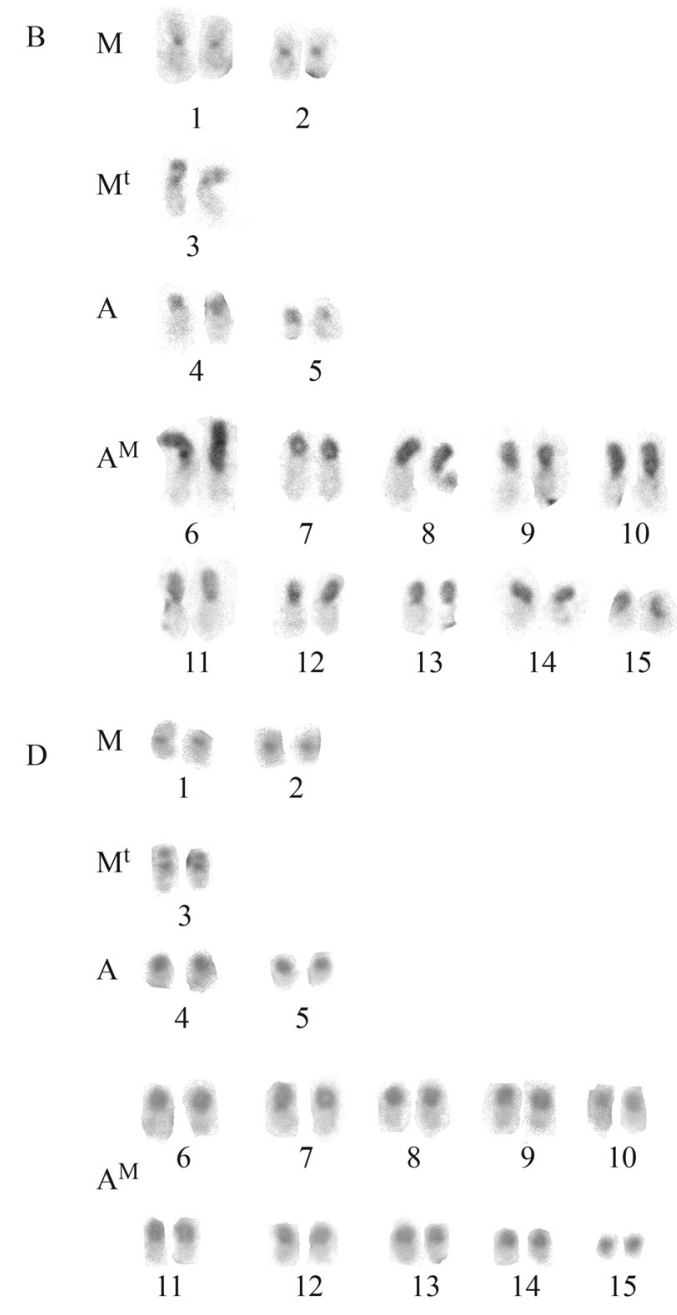

Figure 1 - Karyotypes of Frieseomelitta dispar (A and B) and of Frieseomelitta francoi (C and D) after: conventional coloration (A and C) and C-banding (B and D). 


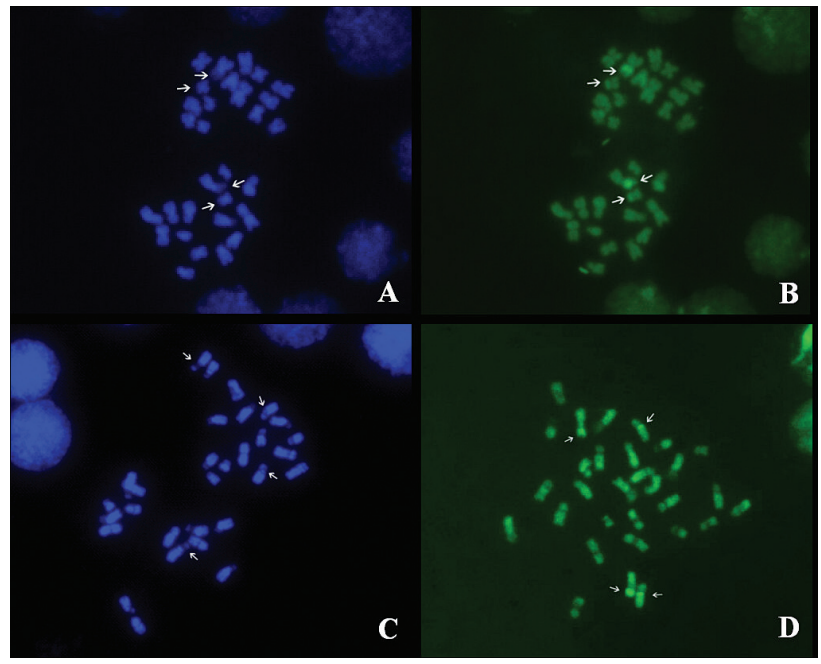

Figure 2 - Metaphases of a Frieseomelitta dispar male, $\mathrm{n}=15$ chromosomes (A and B) and of a Frieseomelitta francoi female, $2 \mathrm{n}=30$ (C and D) after: DAPI (A and $\mathrm{C}$ ) and $\mathrm{CMA}_{3}(\mathrm{~B}$ and $\mathrm{D})$ staining. The arrows indicate $\mathrm{CMA}_{3}{ }^{+} / \mathrm{DAPI}{ }^{-}$bands.

The occurrence of the $\mathrm{M}^{\mathrm{t}}$ chromosome and other features of the karyotype formulae suggest a closer relationship between $F$. dispar and $F$. francoi. However, the available phylogeny separates these species in different groups (Camargo and Pedro, 2003) and our results with fluorochromes staining also point in that direction. In case that the phylogenetic hypotheses based on morphology are correct, the $\mathrm{M}^{\mathrm{t}}$ chromosomes had an independent origin, which, however, is inconsistent with the karyotypic conservation observed in this genus.

Our results confirmed the chromosome number conservation in the karyotypes of Frieseomelitta species and suggest that a rare pericentric inversion could constitute a synapomorphy for a group including $F$. dispar, F. francoi, and $F$. varia. Further cytogenetic analyses including other Frieseomelitta species using more refined cytogenetic techniques may help to explain the origin of this inversion. The inclusion of species of related genera, such as Trichotrigona and Duckeola, may also help to clarify the cytological mechanisms involved in the origin of the divergent chromosome number $\mathrm{n}=15$ amongst the Meliponini.

\section{Acknowledgments}

We thank Gabriel Augusto Rodrigues de Melo for species identification and Janisete G. Silva for comments on the manuscript. This study had financial support from Fundação de Amparo à Pesquisa do Estado da Bahia (FAPESB).

\section{References}

Camargo JMF and Pedro SRM (2003) Sobre as relações filogenéticas de Trichotrigona Camargo \& Moure (Hymenoptera, Apidae, Meliponini). In: Melo GAR and Santos IA (eds) Apoidea Neotropica: Homenagem aos 90 anos de Jesus Santiago Moure. UNESC, Criciúma, pp 109-122.

Imai HT (1991) Mutability of constitutive heterochromatin (Cbands) during eukaryotic chromosomal evolution and their cytological meaning. Jpn J Genet 66:653-661.

Imai HT, Takahata N, Maruyama T, Daniel A, Honda T, Matsuda Y and Moriwaki K (1988) Theoretical bases for karyotype evolution. II. The fusion burst in man and mouse. Jpn J Genet 63:313-342.

Kerr WE (1972) Numbers of chromosomes in some species of bees. J Kansas Entomol Soc 45:11-122.

Moure JS, Urban D and Melo GAR (2007) Catalogue of Bees (Hymenoptera, Apoidea) in the Neotropical Region. Sociedade Brasileira de Entomologia, Curitiba, 1058 pp.

Pompolo SG and Campos LAO (1995) Karyotypes of two species of stingless bees, Leurotrigona muelleri and Leurotrigona pusilla (Hymenoptera, Meliponinae). Rev Bras Genet 18:181-184.

Pompolo SG and Takahashi CS (1990) Chromosome numbers and C-banding in two wasp species of the genus Polistes (Hymenoptera, Polistinae, Polistinii). Insectes Soc 37:251257.

Rasmussen C and Cameron SA (2010) Global stingless bee phylogeny supports ancient divergence, vicariance, and long distance dispersal. Biol J Linn Soc 99:206-232.

Rocha MP, Pompolo SG and Campos LAO (2003) Citogenética da tribo Meliponini (Hymenoptera, Apidae). In: Melo GAR and Santos IA (eds) Apoidea Neotropica: Homenagem aos 90 anos de Jesus Santiago Moure. UNESC, Criciúma, pp 311-320.

Schweizer D (1980) Simultaneous fluorescent staining of R bands and specific heterochromatic regions (DA-DAPI bands) in human chromosomes. Cytogenet Cell Genet 27:190-193.

Silveira FA, Melo GAR and Almeida EAB (2002) Abelhas Brasileiras. Sistemática e Identificação. Fundação Araucária, Belo Horizonte, $253 \mathrm{pp}$.

Sumner AT (1972) A simple technique for demonstrating centromeric heterochromatin. Exp Cell Res 75:304-306.

Associate Editor: Yatiyo Yonenaga-Yassuda

License information: This is an open-access article distributed under the terms of the Creative Commons Attribution License, which permits unrestricted use, distribution, and reproduction in any medium, provided the original work is properly cited. 